\title{
Impacts and adaptation to climate change in the Mediterranean coastal areas: the CIRCLE-MED initiative
}

\author{
F. D. Santos $\cdot$ T. Y. Stigter $\cdot$ N. Faysse $\cdot$ \\ T. C. Lourenço
}

Received: 17 October 2013/Accepted: 26 October 2013/Published online: 14 November 2013

(C) Springer-Verlag Berlin Heidelberg 2013

The Mediterranean region is considered one of the world's climate change hot spots (Giorgi 2006; Diffenbaugh et al. 2007; García et al. 2011). Observations in the Mediterranean area over the last decades indicate clear signs of a changing climate. Statistically significant increasing trends in heat waves and decreasing trends in cold spells have been reported (Kuglitsch et al. 2009, 2010). The land area surrounding the Mediterranean has experienced ten of the twelve driest winter seasons since 1902 in just the last 20 years (Hoerling et al. 2011). The more frequent droughts, together with heat-related stresses, are also contributing to increased tree mortality (Allen et al. 2010; Bertini et al. 2011) and forest fires (Pausas and Fernández-Muñoz 2012) in the Mediterranean region, further exacerbating desertification that is already occurring in parts of the region. Models foresee major future changes in climate and related direct impacts in the area, such as marked increases in temperatures, strong decreases in rainfall (García et al. 2011), and sea-level rise (Rahmstorf et al. 2011).

Many Mediterranean socioeconomic sectors are vulnerable to these climatic changes. The projected decrease

\footnotetext{
F. D. Santos - T. C. Lourenço

SIM-CCIAM, Faculty of Sciences, University of Lisbon,

Lisbon, Portugal

e-mail: fdsantos@siam.fis.fc.ul.pt

T. C. Lourenço

e-mail: tcapela@siam.fis.fc.ul.pt

T. Y. Stigter $(\bowtie)$

Water Science \& Engineering Department, UNESCO-IHE,

Delft, The Netherlands

e-mail: t.stigter@unesco-ihe.org

N. Faysse

G-Eau Research Unit, CIRAD, Montpellier, France

e-mail: faysse@cirad.fr
}

in precipitation is very likely to limit the water availability, which is already a problem in many parts of the region, particularly for agriculture, which consumes $60 \%$ to more than $80 \%$ of the water supply (EEA 2009). Climate change in the Mediterranean will increase the need for irrigation in agriculture, but future irrigation will be constrained by reduced runoff, reduced recharge of aquifers, and competition from other sectors, in particular human settlements and energy. The pressure on available water resources and consequent risk of overexploitation is therefore likely to increase.

Coastal areas are specifically vulnerable to climate change, a major driver of which being sea-level rise (SLR), which has already been taking place in the past decades. In the northwest Mediterranean, the average SLR rate between 1990 and 2010 was $3.4 \mathrm{~mm} \mathrm{year}^{-1}$ (Calvo et al. 2011). SLR is expected to accelerate in the future, e.g., predicted to be in the range of $0.62-1.48 \mathrm{~m}$ up to 2100 by the RCP4.5 scenario (Rahmstorf et al. 2011). For coastal impact studies, the appropriate variable is local relative SLR that is also determined by the subsidence of coastal land, subsurface resource extraction, glacial isostatic rebound, and tectonic movements. The major impacts of SLR are changes in coastal wetlands, increased coastal flooding and erosion, and saltwater intrusion into estuaries and deltas. More frequent and severe weather and climatic events will further enhance these phenomena in the short term, whereas on longer timescales changes in wind and wave climate can interfere with sediment transport leading to greater erosion or accretion.

Other concerns, particularly for the coastal ecosystems, are an increase in seawater temperature and acidity. In the Mediterranean, sea surface temperatures have increased $0.43{ }^{\circ} \mathrm{C}$ from 1957 to 2008 (Belkin 2009). Periods of extreme seawater temperature have contributed to 
mortality events that affected many invertebrate species in the summers of 1999, 2003, and 2006 (Calvo et al. 2011; Crisci et al. 2011). The increasing water temperatures are also driving the northward spread of warm-water species, leading to the "tropicalization" of the Mediterranean marine fauna (Ben Rais Lasram and Mouillot 2008; Galil 2011). Seawater acidification, mainly due to the uptake of atmospheric $\mathrm{CO}_{2}$, is expected to enhance the production of sea grass and macroalgae and, together with sea surface warming, to exacerbate coral bleaching and mortality. It may also reduce the calcification of shellfish and have potential impacts on aquaculture (Barton et al. 2012).

All the referred changes are expected to take place in coastal areas that are already under strong pressures from non-climate drivers, such as urbanization, coast-ward migration of people, tourism, intensive irrigated agriculture, dam building, industries, and port facilities. Humaninduced drivers are the primary drivers of change in coastal aquifers, lagoons, estuaries, deltas, and wetlands but climate-induced drivers are likely to increasingly aggravate the existing problems and to create new risks.

Despite the existing studies on climate change in the Mediterranean area, there are still many knowledge gaps, particularly regarding i) the way global changes can be downscaled to build more detailed scenarios of changes at a local level (i.e., on local coastal and freshwater, surface and groundwater systems, as well as associated ecosystems and water users), and ii) how societies can engage into adaptation strategies as part of these scenarios of changes. To address this challenge, the CIRCLE-MED joint research initiative was launched in 2007 under the EU-funded CIRCLE ERA-Net framework (Climate impact research and response coordination for a larger Europe; www.circleera.eu), with the support of five Mediterranean country partners: Portugal, Galicia-Spain, France, Italy, and Israel. This was CIRCLE's first joint call for research projects and had as theme "Integrated Coastal Zones and Water Management" focusing on the Mediterranean region, defined here on the basis of a climatic area extending from the Western coasts of Portugal and Morocco to those of the East Mediterranean countries. The goal was to develop a network between scientists, policy makers, and stakeholders on knowledge about coastal vulnerability to climate change, on impacts to climate change and on adaptation alternatives. The CIRCLE-MED initiative was keen to associate research teams for both the North and South banks of the Mediterranean.

Eight research projects took place in the frame of the CIRCLE-MED initiative (see http://www.circle-med.net). These projects encompassed teams from the funding countries, as well as from other nations around the Mediterranean coastline, namely Morocco, Tunisia, Croatia, and Albania. The papers published in this supplement of
Regional Environmental Change present the most relevant and innovative methods and the results of five of these eight projects, namely ACIDBIV, AQUIMED, CANTICO, CLIMWAT, and INTERMED.

Two of these projects studied the impact of climate change on selected marine marcroinvertebrate species, using field and laboratory measurements. Sarà et al. (this volume) focus on biological (i.e., cellular, ecophysiological, and behavioral) responses of mussels, gastropods, and sponges to a predicted increase in water temperature in the intertidal zone and consequent changes of its ecosystem services, further supporting their results by ecological modeling. These results indicate that water temperature increase will impact Mediterranean intertidal ecosystems by impairing the physiology of key organisms and favoring the survival of alien, invasive species.

Range et al. (this volume) address the effects of seawater acidification on a number of biological responses on one mussel and two clam species, including growth and calcification, at two locations, namely a coastal lagoon in South Portugal and in the Northern Adriatic Sea. Their $\mathrm{CO}_{2}$ perturbation experiments produce contrasting responses according to species and locations. Whereas the effects of acidification on growth and calcification in water of the Adriatic Sea were pronounced, in the coastal lagoon, these effects were much less evident, probably buffered by a high carbonate content of the water. This clearly shows the need to study all other interacting or mediating factors that cause the effects of acidification to be locally variable, even for the same species. In fact, both the studies of Sarà et al. (this volume) and Range et al. (this volume) reveal large variations in macroinvertebrate response to the imposed changes (in temperature and $\mathrm{pH}$, respectively), underpinning the need for species-specific and location-specific adaptation measures.

Lamon et al. (this volume) present a joint application of simulation models for atmospheric and marine circulation dynamics, as well as for biochemical processes affecting nutrient concentrations in the Mediterranean Sea, at the Gulf of Gabès. The latter are further driven by different socioeconomic scenarios affecting nutrient emissions, making it an interesting integrated study on climate and socioeconomic changes, two factors that are also interrelated. Despite the recognized uncertainty in the models, their calibration, as well as the downscaling of the climate scenarios, the results are believed to be valuable for regional risk assessment, supporting the correct targeting of adaptation measures.

The paper of Stigter et al. (this volume) assesses and compares the predicted evolution of climate and its impact on coastal aquifers in three Mediterranean areas in Portugal, Morocco, and Spain. Three main aspects are jointly addressed, namely (1) a short-term shift in regime and 
long-term reduction in rainfall, affecting aquifer recharge; (2) an increase in temperature, affecting crop water demands, and (3) sea level rise, causing a shift in the fresh/ salt groundwater interface. Uncertainties related to chosen climate model runs, downscaling techniques, and recharge calculation methods are addressed. Results demonstrate that certain aspects of current groundwater management and future impacts are clear, and strategies either targeting supply (e.g., enhanced aquifer recharge and reclaimed wastewater use) or demand (e.g., increased water use efficiency and change in crop type) need to be implemented.

Public awareness of the potential impact of climate change and of the need to adapt is certainly not a given and can be extremely difficult to attain. This is illustrated by the results of Sarà et al. (this volume) that reveal minimal conservation efforts for intertidal communities, because of the low awareness of local stakeholders regarding the value of such ecosystems. Mechanisms to deal with public awareness raising and participation are addressed by Faysse et al. (this volume) on the implementation of participatory foresight analyses to explore agricultural and water management options for adaptation to climate change in three Mediterranean areas. Despite the many difficulties that need to be overcome, such participatory analyses can be implemented by framing the climate change issue in a broader agenda for discussion with the actors. Knowledge of the local context, building of trust between researchers and actors, and an interdisciplinary approach including social and natural scientists are crucial elements for the success of raising public awareness and proactive attitudes.

The CIRCLE-MED initiative enabled to obtain very diverse results with regard to climate change impacts and opportunities for adaptation in the Mediterranean. Coastal areas of the Mediterranean appeared a very relevant "laboratory" for studying these issues. CIRCLE-MED also permitted to strengthen networks between scientists, local stakeholders, and decision makers around such issues. Thanks to frequent interactions between the funding agencies and research teams, it also enabled to share the gained knowledge with local, national, European, and international adaptation decision makers. The five papers are believed to provide original approaches to the illustration and partial understanding of the complexity of climate change effects in Mediterranean coastal areas, but also show the need to deal with them on a local and regional scale, despite the inherent uncertainty. This demand for local process-driven research has resulted in the CIRCLE-2 ERA-NET follow-up initiative, which was initiated in 2010 and currently represents a network of 34 institutions from 23 countries where knowledge on good practices in climate change-related research programming and funding can be shared.

\section{References}

Allen CD et al (2010) A global overview of drought and heat-induced tree mortality reveals emerging climate change risks for forests. For Ecol Manage 259(4):660-684

Barton A et al (2012) The Pacific oyster. Crassostera gigas, shows negative correlation to naturally elevated carbon dioxide levels: Implications for near-term ocean acidification effects, Limnology and Oceanography 57(3):698-710

Belkin IM (2009) Rapid warming of large marine ecosystems. Prog Oceanogr 81(1-4):207-213

Ben Rais Lasram F, Mouillot D (2008) Increasing southern invasion enhances congruence between endemic and exotic Mediterranean fish fauna. Biol Invasions 11(3):697-711

Bertini G, Amoriello T, Fabbio G, Piovosi M (2011) Forest growth and climate change: evidences from the ICP-Forests intensive monitoring in Italy. iForest 4:262-267

Calvo E et al (2011) Effects of climate change on Mediterranean marine ecosystems: the case of the Catalan Sea. Clim Res 50(1):1-29

Crisci et al (2011) Temperature anomalies and mortality events in marine communities: insights on factors behind differential mortality impacts in the NW Mediterranean. PLoS ONE 6(9):e23814

Diffenbaugh NS, Pal JS, Giorgi F, Gao X (2007) Heat stress intensification in the Mediterranean climate change hotspot. Geophys Res Lett 34:6

EEA, 2009, Water resources across Europe - confronting water scarcity and drought, European Environment Agency, Copenhagen, Report $\mathrm{N}^{\circ} 2 / 2009,1-55$

Galil BS (2011) The alien crustaceans in the Mediterranean Sea: an historical overview. Invad Nat Spring Ser 6:377-401

García-Ruiz JM, López-Moreno JI, Vicente-Serrano SM, LasantaMartínez T, Beguería S (2011) Mediterranean water resources in a global change scenario. Earth Sci Rev 105:121-139

Giorgi F (2006) Climate change hot spots. Geophys Res Lett 33:L08707

Hoerling $\mathrm{M}$ et al (2011) On the increased frequency of Mediterranean drought. J Clim 25:2146-2161

Kuglitsch FG, Toreti A, Xoplaki E, Della-Marta PM, Luterbacher J, Wanner H (2009) Homogenization of daily maximum temperature series in the Mediterranean. J Geophys Res-Atmospheres 114:D15108. doi:10.1029/2008JD011606

Kuglitsch FG, Toreti A, Xoplaki E, Della-Marta PM, Zerefos CS, Turkes M, Luterbacher J (2010) Heat wave changes in the eastern Mediterranean since 1960. Geophys Res Lett 37:L04802. doi:10.1029/2009GL041841

Pausas JG, Fernández-Muñoz S (2012) Fire regime changes in the Western Mediterranean basin: from fuel-limited to droughtdriven fire regimes. Clim Change 110(1-2):215-226

Rahmstorf S, Perrette M, Vermeer M (2011) Testing the robustness of semi-empirical sea-level projections. Clim Dyn 39(3-4):861-875 